\title{
Pattern of intracranial tumours in a tertiary hospital in Ghana
}

\author{
Ubong Ekpene, Mawuli Ametefe, Henry Akoto, Patrick Bankah, Teddy Totimeh, George Wepeba \\ and Thomas Dakurah
}

Ghana Med J 2018; 52(2): 79-83 doi: http://dx.doi.org/10.4314/gmj.v52i2.3

\author{
Neurosurgery Unit, Department of Surgery, Korle Bu Teaching Hospital, P.M.B KB77, Accra. Ghana
}

Corresponding author: Dr Ubong Ekpene

E-mail: ubongekpene@yahoo.com

\author{
Conflict of interest: None declared
}

\section{SUMMARY}

Objective: This study seeks to describe the pattern of intracranial tumours in Korle Bu Teaching Hospital (KBTH) based on patient demographics, clinical presentation, spatial distribution of tumour and histological findings.

Method: The study design is retrospective and descriptive. Data was obtained from the clinical records of patients with intracranial tumours treated in our neurosurgery unit between January 2010 to December 2015, and histology reports obtained from the histopathology unit. Patients with intracranial tumours without definitive histological diagnosis were excluded.

Results: Of the 102 histologically diagnosed brain tumours, out of 335 brain tumour cases seen in the period under review, $58(56.9 \%)$ were females and $44(43.1 \%)$ were males $(\mathrm{p}=0.031)$. Gliomas were the commonest intracranial tumours - 39(38.2\%) followed by Meningiomas 37(36.2\%) and Pituitary Adenoma - 9(8.8\%). Astrocytoma was the commonest type of Glioma comprising 30(77\%) of the 39 cases. Meningotheliomatous meningioma was the commonest type of meningioma with $11(29.7 \%)$ of 37 cases. Of the 39 Gliomas $17(43.6 \%)$ were males and 22(56.4\%) were females, while for the Meningioma 17(46\%) were males and 20(54\%) were females. The commonest symptom was headache $(64 \%)$ and the commonest tumour location was supratentorial $(77.5 \%)$. The crude incidence rate of intracranial tumours in this study was 1.34 per 100,000 populations per year.

Conclusion: Gliomas are the commonest intracranial tumours seen in our series. Overall, females were more commonly affected than males in most brain tumours in this series, including both gliomas and meningiomas.

Funding: Not declared

Keywords: Intracranial tumours, glioma, tumour pattern, Incidence.

\section{INTRODUCTION}

Intracranial tumours arise from the brain or its surrounding tissues. They are a major cause of morbidity and mortality worldwide. The annual, global, age standardized incidence of primary malignant intracranial tumours is approximately 3.7 per 100,000 for males and 2.6 per 100,000 for females. ${ }^{1}$ In the US the incidence rate of all primary malignant and non-malignant brain and CNS tumours between 2008 to 2012 was 21.97 cases per 100,000 , the rate being higher in females $(23.95 / 100,000$ for a total count of 206,565 incident tumours) than males (19.82/100,000 for a total count of 150,271 incident tumours). ${ }^{2}$ They are commoner among Caucasians. ${ }^{3}$ Gliomas are the commonest group of intracranial neoplasms in both adults and children, ${ }^{3,4}$ and are commoner in males while meningiomas are commoner in females.

Outcome of intracranial tumours varies with tumour type, location, stage at diagnosis, age of patient, functional performance score and extent of tumour resection. ${ }^{6}$
Patients with intracranial tumours in Africa typically have delayed diagnosis due to late presentation, which has been reported to be 2 years on average, ${ }^{5}$ thus making the prognosis bleak. Various institution-based epidemiologies of intracranial tumours have been reported in several places in Africa ${ }^{7-10}$ but the true incidence in sub-Saharan Africa is not known ${ }^{11}$ thus proper health budgeting and planning is far from optimal.

There is very limited data on the patterns of intracranial tumours in Ghana. ${ }^{12,13}$ The objective of this study is to determine the pattern of intracranial tumours in neurosurgical patients managed in Korle Bu Teaching Hospital based on the following parameters; demographics, presenting symptoms, spatial distribution and histopathology. This may be extrapolated to the Ghanaian population as Korle $\mathrm{Bu}$ Teaching Hospital is the foremost neurosurgical centre in Ghana where majority of the intracranial tumour patients are referred. 


\section{METHODS}

This study is a retrospective, descriptive study. Data was obtained from the hospital records of patients with intracranial tumours, diagnosed by Computed Tomography scan and/or Magnetic Resonance Imaging and evaluated in the neurosurgical unit of Korle Bu Teaching Hospital between January 2010 and December 2015. Korle Bu Teaching Hospital is the foremost teaching hospital in Ghana and the third largest teaching hospital in Africa, with a bed capacity of $2000 .{ }^{14}$

Majority of the intracranial tumour cases in the country are treated in this hospital, being the national referral centre. An average of 2 new cases of intracranial tumour is seen at the neurosurgical clinic of the hospital every week besides those that present at the emergency room. There are three other centres where very few brain tumour surgeries are done in Ghana.

Data were obtained from ward records, theatre records and histopathology records of the hospital. Records of all the patients who have undergone different types of surgery for intracranial tumours were obtained from the hospital's theatre register. of the hospital. Only those with histologically diagnosed tumours were included in the data analysis. The following data specifics were extracted and analysed; patients' demographics (age and gender), presenting symptoms and signs, and histopathology of the tumour. For the avoidance of doubt, those without histopathology of their tumour were excluded.

The population of Ghana during the study period, estimated to be $25,000,000$ from the 2012 census, ${ }^{15}$ was taken as the average of the mid-year estimates for 2010 to 2015. The crude incidence rate was calculated from the total number of cases that presented at the Korle $\mathrm{Bu}$ Teaching Hospital over the total population multiplied by 100,000 , and expressed as the number of cases per 100.000 populations per year. The population of Accra is estimated to be 2.27 million. ${ }^{16}$ Data were summarized using percentages, tables and charts, and analysed with SPSS version 21.

\section{RESULTS}

A total of 335 patients with intracranial tumours were seen in the period under review out of which 274 had surgical interventions. The surgical interventions included; stereotactic biopsy, endoscopic biopsy, craniotomy and excision biopsy, endoscopic third ventriculostomy and ventriculoperitoneal shunting.
Out of the 335 patients, 102 had histologically confirmed tumours described according to the WHO classification of nervous system tumours. The overall gender distribution is shown in Table 1.

Table 1 Overall gender distribution of intracranial tumours seen between 2010 and 2015

\begin{tabular}{l|lll}
\multicolumn{2}{l}{ Total } & Male & Female \\
\hline $\begin{array}{l}\text { Total number seen (+/- } \\
\text { histology) }\end{array}$ & 335 & $164(49 \%)$ & $171(51 \%)$ \\
$\begin{array}{l}\text { Numbers operated } \\
\text { Histological diagnosis }\end{array}$ & 274 & $135(49.3 \%)$ & $139(50.7 \%)$ \\
& 102 & $44(43.1 \%)$ & $58(56.9 \%)$
\end{tabular}

Further breakdown of the mean age distribution relative to gender is as shown in Table 2 below.

Table 2 Mean age distribution and Gender

\begin{tabular}{|c|c|c|c|c|}
\hline & Total & Male & Female & p-value \\
\hline \multirow{3}{*}{$\begin{array}{l}\text { No. of patients } \\
\text { Age range in years } \\
\text { Overall mean age in years }\end{array}$} & 102 & $44(43.1 \%)$ & $58(56.9 \%)$ & 0.031 \\
\hline & & $2-73$ & $1-73$ & \\
\hline & & 31 & 33 & 0.458 \\
\hline
\end{tabular}

Table 3 shows the commonest symptoms and signs in these patients with intracranial tumours. The percentages were calculated based on 62 patients with detailed symptomatology.

Table 3 Main symptoms and signs

\begin{tabular}{l|cc} 
Symptoms/signs & Frequency & \% \\
\hline Headache & 41 & 66.1 \\
Visual disturbances & 21 & 33.9 \\
Hemiparesis & 15 & 24.2 \\
Seizures & 12 & 19.4 \\
Gait abnormality & 7 & 11.2 \\
Proptosis & 5 & 8.1 \\
Skull swelling & 5 & 8.1 \\
Vomiting & 4 & 6.4 \\
Cranial nerve palsy & 4 & 6.4 \\
Altered mentation & 3 & 4.8 \\
Speech abnormality & 3 & 4.8 \\
Hearing impairment & 2 & 3.2
\end{tabular}

The histopathological distribution of tumours relative to gender is as shown on Table 4.

Table 4 Tumour histopathology and gender distribution, $\mathrm{n}(\%)$

\begin{tabular}{l|ccc} 
Tumour & Number & Male & Female \\
\hline Glioma & $39(38.2 \%)$ & $17(43.6 \%)$ & $22(56.4 \%)$ \\
Meningioma & $37(36.2 \%)$ & $17(46 \%)$ & $20(54 \%)$ \\
Pituitary adenoma & $9(8.8 \%)$ & $3(33.3 \%)$ & $6(66.7 \%)$ \\
Metastatic tumour & $8(7.9 \%)$ & $2(25 \%)$ & $6(75 \%)$ \\
Craniopharyngioma & $3(2.9 \%)$ & $1(33.3 \%)$ & $2(66.7 \%)$ \\
Haemangioblastoma & $1(1 \%)$ & 0 & $1(100 \%)$ \\
Pineocytoma & $1(1 \%)$ & $1(100 \%)$ & 0 \\
Hamartoma & $2(2 \%)$ & 0 & $2(100 \%)$ \\
Olfactory neuroblastoma & $1(1 \%)$ & $1(100 \%)$ & 0 \\
Central Neurocytoma & $1(1 \%)$ & $1(100 \%)$ & 0
\end{tabular}




\section{Original Article}

Glioma is the commonest with $38.2 \%$, slightly higher than meningioma accounting for $36.2 \%$ of tumours seen. Pituitary adenoma and metastatic tumours account for $8.8 \%$ and $7.9 \%$ respectively. In all the aforementioned tumours females tend to have slight preponderance compared to males, but markedly so in the metastatic group with three-quarter being females. Overall, there were also more female patients with intracranial tumours.

Table 5: Histological type and age distribution

\begin{tabular}{|c|c|c|c|c|c|}
\hline Histo logical type & Number & $\begin{array}{l}\text { Mean age-yr } \\
\text { (Median/mode) }\end{array}$ & $\begin{array}{l}< \\
16 y r\end{array}$ & $\begin{array}{l}16- \\
45 y r\end{array}$ & $>45 \mathrm{yr}$ \\
\hline \multicolumn{6}{|l|}{ Tumours of neuroepithelial tissue } \\
\hline Pilocytic Astrocytoma & 10 & $8(4 / 4)$ & 8 & 2 & 0 \\
\hline Low grade glioma & 12 & $12(13 / 17)$ & 7 & 5 & 0 \\
\hline Anaplastic Astrocytoma & 1 & 32 & 0 & 1 & 0 \\
\hline Glioblastoma & 10 & 57 & 1 & 0 & 9 \\
\hline Medulloblastoma & 3 & $11(8)$ & 2 & 1 & 0 \\
\hline Ependymoma & 3 & $16(11)$ & 2 & 1 & 0 \\
\hline Central Neurocytoma & 1 & 33 & 0 & 1 & 0 \\
\hline Olfactory Neuroblastoma & 1 & 75 & 0 & 0 & 1 \\
\hline Pineocytoma & 1 & 18 & 0 & 1 & 0 \\
\hline Tumours of meninges (Meningioma) & 37 & 44 & 1 & 18 & 18 \\
\hline Haemangioblastoma & 1 & 20 & 0 & 1 & 0 \\
\hline \multicolumn{6}{|l|}{ Tumours of the sellar region } \\
\hline Pituitary adenoma & 9 & 43 & 0 & 6 & 3 \\
\hline Craniopharyngioma & 3 & $11(13)$ & 2 & 1 & 0 \\
\hline Metastatic tumours & 8 & 56 & 1 & 1 & 6 \\
\hline \multicolumn{6}{|l|}{ Hamartoma } \\
\hline Heterotopic intracranial thyroid & 1 & 30 & 0 & 1 & 0 \\
\hline tissue & 1 & 13 & 1 & 0 & 0 \\
\hline Benign fibro-cemento-osseous lesion & & & & & \\
\hline
\end{tabular}

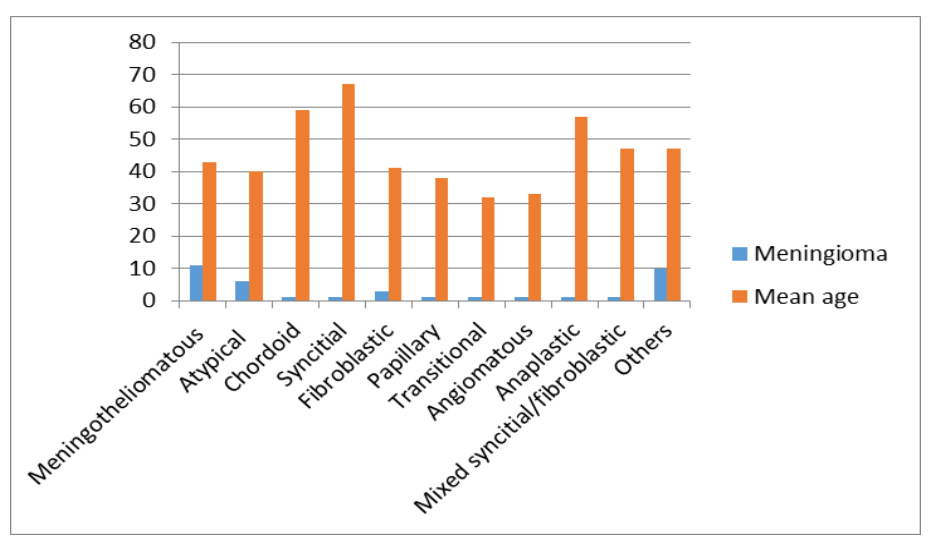

Figure 1 Histological types of meningioma and mean age

Table 6 Tumour distribution based on location.

\begin{tabular}{l|cc}
\multicolumn{1}{c}{ Tumour type } & $\begin{array}{c}\text { Supratentorial } \\
\text { Infratento- } \\
\text { rial }\end{array}$ \\
\hline Glioma & $20(51.3 \%)$ & $19(48.7 \%)$ \\
Central Neurocytoma & $1(100 \%)$ & 0 \\
Olfactory Neuroblastoma & $1(100 \%)$ & 0 \\
Pineocytoma & $1(100 \%)$ & 0 \\
Meningioma & $36(97.3 \%)$ & $1(2.7 \%)$ \\
Metastatic & $6(75 \%)$ & $2(25 \%)$ \\
Haemangioblastoma & 0 & $1(100 \%)$ \\
Craniopharyngioma & $3(100 \%)$ & 0 \\
Pituitary adenoma & $9(100 \%)$ & 0 \\
Hamartoma & $2(100)$ & 0 \\
Total & $79(77.5 \%)$ & $23(22.5 \%)$ \\
\end{tabular}

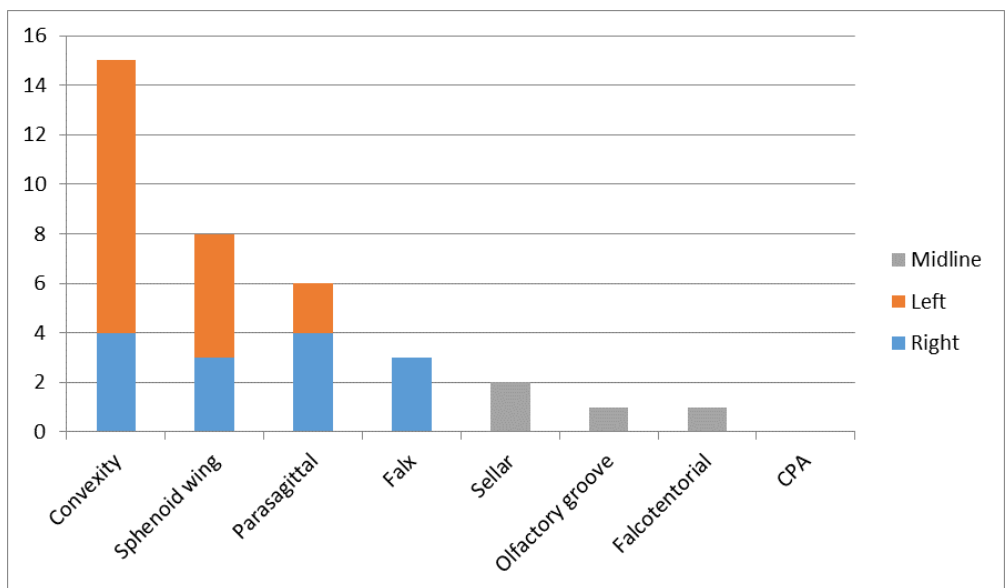

Figure 2 The distribution of meningioma based on location.

The majority of tumours $(77.5 \%)$ were located in the supratentorial compartment (Table 6). The distribution of meningioma based on location is shown in Figure 2. Most of the tumours were lateralized to the left. Convexity meningioma is the commonest making up $15(40.5 \%)$ of 37 cases, followed by sphenoid wing meningioma and parasagittal meningioma with $8(21.6 \%)$ and $6(16.2 \%)$ respectively.

\section{DISCUSSION}

Intracranial tumours are relatively common neurosurgical conditions and are associated with high morbidity and mortality. Patterns of distribution of these tumours vary across the globe. ${ }^{1-5,7-10,12,13,17,18}$ This study sought to determine the pattern of intracranial tumours in neurosurgical patients with intracranial tumours who presented at Korle Bu Teaching Hospital, Accra, Ghana for treatment between January 2010 and December 2015. 102 histologically diagnosed intracranial tumours out of 335 radiologically diagnosed intracranial tumours were included in the study. The low histological rate is mostly due to missing data resulting from poor record keeping. Some of the patients neither had biopsy before their demise nor a post mortem after their demise. Some only had cerebrospinal fluid diversion procedures before their demise.

The total number of intracranial tumours seen over the study period showed female preponderance (see Table 1) similar to the findings by Soyemi SS et al. ${ }^{8}$ This is shown to be statistically significant $(\mathrm{p}=0.031)$ in Table 2 . 
The mean age of presentation of intracranial tumour relative to gender (including paediatric patients) showed that females presented at a slightly higher age in the adult population, but earlier than males in the paediatric population (see Table 2). This was, however, not statistically significant $(\mathrm{p}=0.458)$

Headache $(66.1 \%)$ was the commonest symptom as seen in one other study, ${ }^{5}$ closely followed by visual impairment (33.9\%), hemiparesis $(24.2 \%)$ and seizures $(19.4 \%)$. Andrew et $\mathrm{al}^{12}$ reported seizures as the most common symptom in their case series. Some other studies reported focal neurologic deficit as the commonest symptom. ${ }^{17,18}$ Gliomas were the commonest tumour type, accounting for $38.2 \%$ of intracranial tumours followed closely by meningioma (36.2\%). This is in keeping with findings in other studies ${ }^{5,7-10,17,18}$ Although gliomas are reported to be commoner in males, ${ }^{3,5,7}$ there was a slight female preponderance in this study, which is similar to an earlier publication in Tema, Ghana by Andrews et al. ${ }^{12}$ This may be the true picture or just a trend suggesting that females tend to seek medical treatment more than men with similar conditions in Ghana.

Meningioma was commoner in females as reported in other studies. ${ }^{2,4,5,7-11,17,18}$ It is also worthy of note that pituitary adenoma, metastatic tumours and craniopharyngioma, which followed gliomas and meningiomas in that order, in terms of prevalence, were all slightly commoner in females. Glioblastoma and pilocytic astrocytoma were the commonest gliomas with the former commoner in the $>45$ years' age group similar to the CBTRUS study, ${ }^{2}$ and the latter in the under 16 years' age group. Yusoff et al ${ }^{19}$ on the other hand, reported a lower age bracket of 15-45 years as the commonest age range for glioblastoma in rural north east Malaysia. As stated above Pilocytic astrocytoma is the commonest paediatric intracranial tumour, followed by medulloblastoma and ependymoma in our study, which is similar to one other report. ${ }^{20}$ The mean ages for pituitary adenoma and metastatic tumours were similar to reported age groups. ${ }^{12,20}$

Based on spatial location, supratentorial sites accounted for nearly three-quarter $(77.5 \%)$ of tumour locations as against $22.5 \%$ for infratentorial. Paediatric tumours were mostly located infratentorially and adult tumours supratentorially. Since adults dominated the patient population this may also account for the preponderance of supratentorial tumours. $97.3 \%$ of meningiomas were located in the supratentorial region and convexity meningioma $(40.5 \%)$ predominated, followed by sphenoid wing (21.6\%) and parasagittal meningiomas (16.2\%) respectively. This is similar to the study by Evangelia et al. ${ }^{21}$
Tuberculoma have been reported to mimic malignant tumours ${ }^{22-24}$ but we have not found this among our patients in this series. The crude incidence rate of intracranial tumour in this study was 1.34 per 100,000 populations per year. This may be a gross underestimation of the true incidence since this data was collected in one institution. It may be difficult to determine the true incidence of intracranial population in Ghana since, based on conjecture, some of the patients with intracranial tumours do not present at the hospital but seek alternative care in prayer camps and with herbal remedy providers. Also, intracranial tumour patients are treated in other health facilities within and outside the country. This crude incidence is higher than the 0.44 per 100,000 reported in the Malay population. ${ }^{19}$ The limitation of this study is the relatively small sample size, the low histological diagnosis rate and incomplete data in some patients' records.

\section{CONCLUSION}

The crude incidence rate of intracranial tumour in this study was 1.34 per 100,000 populations per year. Females were more affected by glioma, meningioma, pituitary and metastatic tumours than males, and this was statistically significant when all the tumours were considered irrespective of age. Males presented in the adult population at a mean age slightly earlier than females, but this was not statistically significant.

Headache was the commonest presenting symptom. Tumours were mainly supratentorial. Glioma was the commonest intracranial tumour followed by meningioma. Astrocytoma was the commonest type of Glioma. Meningotheliomatous meningioma was the commonest type of meningioma. The convexity was the commonest location of meningioma. In the paediatric population, pilocytic astrocytoma was the commonest tumour, followed by medulloblastoma and ependymoma.

\section{ACKNOWLEDGEMENT}

We appreciate the contributions of the entire neurosurgical team of Korle Bu Teaching Hospital for the different roles they played in making this study possible.

\section{REFERENCES}

1. GLOBOCAN. Worldwide Incidence and Mortality of Cancer, 2002 [computer program]. Version. Lyon, France: IARC; 2002.

2. CBTRUS. 2015 CBTRUS fact sheet: Primary brain tumors in the United States, 2008-2012. [Online] Available from: http://www.cbtrus.org/factsheet/factsheet.html (Accessed 10th April, 2016)

3. Central Brain Tumor Registry of the United States. CBTRUS Statistical Report: Primary Brain and Central Nervous System Tumors Diagnosed in the 
United States in 2004-2008 February 2012 (March 23, 2012 Revision).[Online] Available from: http0://www.cbtrus.org/2012-NPCR-

SEER/CBTRUS_Report_2004-2008_3-23-

2012.pdf (Accessed 30 th January, 2016)

4. Olasode BJ, Shokunbi MT, Aghadiuno PU. Intracranial neoplasms in Ibadan, Nigeria. East Afr Med J. 2000 Jan; 77(1):4-8.

5. Howlett WP. Intracranial tumours. In: Neurology in Africa. University of Bergen, Bergen, Norway, 2012, 368,

6. Cancer.net. Brain Tumours: Grades and prognostic factors. [Online] Available from: http://www.cancer.net/cancer-types/brain-tumor/grades-and-prognostic-factors (Accessed 15th October, 2017)

7. Mwangombe NJ. Brain tumours at the Kenyatta National Hospital, Nairobi. East Afr Med $J$ 09/2000; 77(8):444-7.

8. Soyemi SS, Olugbenga OO. Spectrum of intracranial tumours in a tertiary health care facility: our findings. Pan African Medical Journal. 2015; 20:24. [Online] Available from: http://www.panafrican-med-journal.com/content/arti-

cle/20/24/pdf/24.pdf (Accessed $2^{\text {nd }}$ November2015).

9. Elhaj A, Osman N, Alobeid A, Abdallah A, Abuidris D. Pattern of Brain Tumours Among Children in Central Sudan. Sudan J Paediatr and Child Health. 2010; 10:32-34.

10. Olufunsho A, Ayokunle AA, Deborah FA. Vincent BF, Duro CD. Cancer distribution pattern in southwestern Nigeria. Tanzan J Health Res. April 2011; 13(2): 1-7.

11. Cancer Research UK. Worldwide cancer mortality statistics. [Online] Available from: http://www.cancerresearchuk.orghealth-professional/cancer-statistics/worldwidecancer/mortality\#heading-Zero (Accessed $25^{\text {th }}$ February 2016)

12. Andrews NB, Ramesh R, Odjidja T. A preliminary study of central nervous system tumours in Tema, Ghana. West Afr J Med.. April-June, 2003;22(2): 167-172.

13. Tagoe NN, Essuman VA, Fordjuor G, Akpalu J, Bankah P, Ndanu T. Neuro-Ophthalmic and Clinical Characteristics of Brain Tumours in a Tertiary Hospital in Ghana. Ghana Med J. 2015;49(3):181-6.

14. http://kbth.gov.gh/about-us.html (Accessed 10 $0^{\text {th }}$ April, 2016)
15. www.ghanaembassy.org/index.php?page $=p$ (Accessed $30^{\text {th }}$ March, 2016)

16. World Population Review (2016). Ghana population 2016. [online] Available from: http://worldpopulationreview.com/countries/ghana-population/ (Accessed $18^{\text {th }}$ June 2016)

17. Preston MS. Descriptive epidemiology of primary tumours of the brain, cranial nerves and cranial meninges in Los Angeles, Calif, USA. Neuroepidemiology. 1989; 8:283-295.[Online] Available from: http://www.karger.com/Article/PDF/110196 (Accessed $2^{\text {nd }}$ December, 2015)

18. Cancer Research UK. Brain, other CNS and intracranial tumours incidence statistics. [Online] Available from: http://www.cancerresearchuk.org/health-professional/cancer-statistics/statistics-by-cancertype/brain-tumours/incidence\#heading-Five (Accessed $2^{\text {nd }}$ November, 2015)

19. Yosoff MR, Abdullah JM, Isa MN. Brain Tumour in rural north east Malaysia. Medical Journal of Islamic Academy of Science. 1998;11(4):121-9.

20. Quinn T. Ostrom, Haley Gittleman, Peter Liao, Chaturia Rouse, Yanwen Chen, Jacqueline Dowling, Yingli Wolinsky, Carol Kruchko, Jill BarnholtzSloan. CBTRUS Statistical Report: Primary Brain and Central Nervous System Tumors Diagnosed in the United States in 2007-2011. Neuro Oncol. 2014 Oct; 16(Suppl 4): iv1-iv63.

21. Evangelia Liouta, Christos Koutsarnakis, Faidon Liakos, George Stranjalis. Effects of intracranial meningioma location, size, and surgery on neurocognitive functions: a 3-year prospective study. $J$ Neurosurg. 2015 December;124(6):1-7.

22. Poonnoose SI , Singh S, Rajshekhar V. Giant cerebellar tuberculoma mimicking a malignant tumour. Neuroradiology. 2004 Feb; 46(2):136-9. Epub 2004 Jan 9.

23. Rico-Cotelo M, Serramito-García R, Arán-Echabe E, Gelabert-González M. Intracranial tuberculoma mimicking malignant tumour]. Rev Neurol. 2012 Sep 1; 55(5):279-82.

24. Javier AB , Luz FS, Miryam A, Luis EB . Solitary intracranial tuberculoma mimicking a malignant tumor in a patient without tubercular lesions or a history of disease: a case report. Bosn J Basic Med Sci. 2013 May; 13(2): 129-133. 